Int. J. Dev. Biol. 54: 1389-1396 (2010)

doi: $10.1387 / \mathrm{ijdb}$.093006jg

\title{
Expression of DOF genes identifies early stages of vascular development in Arabidopsis leaves
}

\author{
JASON GARDINER\#, IRA SHERR\# and ENRICO SCARPELLA* \\ Department of Biological Sciences, University of Alberta, Edmonton, Alberta, Canada
}

\begin{abstract}
The sequence of events underlying the formation of vascular networks in the leaf has long fascinated developmental biologists. In Arabidopsis leaves, vascular-precursor procambial cells derive from the elongation of morphologically inconspicuous ground cells that selectively activate expression of the HD-ZIP III gene ATHB8. Inception of ATHB8 expression operationally defines acquisition of a typically irreversible preprocambial cell state that preludes to vein formation. A view of the constellation of genes whose expression is activated at preprocambial stages would therefore be particularly desirable; however, very few preprocambial gene expression profiles have been identified. Here, we show that expression of three genes encoding members of the DOF family of plant-specific transcription factors is activated at stages overlapping onset of $A T H B 8$ expression. Expression of DOF genes is initiated in wide domains that become confined to sites of vein development. Congruence between DOF expression fields and zones of vein formation persists upon experimental manipulation of leaf vascular patterning, suggesting that DOF expression identifies consistently recurring steps in vein ontogeny. Our results contribute to defining preprocambial cell identity at the molecular level.
\end{abstract}

KEY WORDS: Arabidopsis thaliana, leaf development, vein patterning, procambium, auxin transport

\section{Introduction}

The vascular system of plants is composed of strands that extend and intersect throughout all organs (Esau, 1965). Vascular strands are responsible for long-distance transport of water and nutrients, and are source of signals that act locally, to direct the development of neighboring cells, and systemically, to coordinate the initiation of new shoot organs with that of new roots (Berleth and Sachs, 2001). Sites of vascular strand differentiation are defined during organ development by emergence of continuous lines of elongated vascular-precursor procambial cells (Esau, 1943).

Few natural phenomena have attracted more widespread attention than the patterned formation of vascular strands in the leaf. From a developmental standpoint, the process is particularly fascinating because it seems to be organized de novo in each leaf primordium. At early stages of leaf ontogeny, in fact, the cells located beneath the epidermis appear as a morphologically homogeneous population of tightly connected, polygonal, isodia- metric cells ('ground cells') (Smith, 1934; Foster, 1936, 1952); during leaf development, complementary, anatomically inconspicuous subsets of ground cells will differentiate to generate procambial strands and the photosynthetic tissue of the leaf, the mesophyll.

The molecular details of the mechanism by which cells acquire procambial identity during organ development are not entirely clear, but transport and transduction of the plant signaling molecule auxin have long been implicated in defining paths of vascular differentiation (Berleth et al., 2000; Sachs, 1981). In leaf development, ground cells are directed towards procambial fate through induction of wide domains of expression of the PINFORMED1 (PIN1) auxin exporter and of the auxin response

\footnotetext{
Abbreviations used in this paper: CFP, cyan fluorescent protein; DAG, days

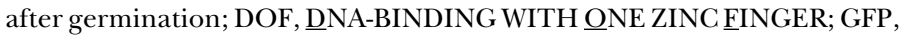
green fluorescent protein; HD-ZIP III, class III HOMEODOMAIN-LEUCINE ZIPPER; LUT, look-up table; NPA, 1-N-naphthylphthalamic acid; YFP, yellow fluorescent protein.
}

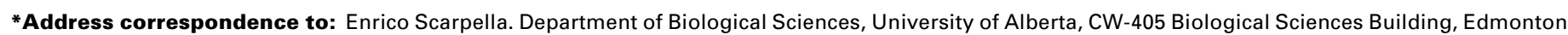
AB, Canada T6G 2E9. Fax: +1-780-4929234. e-mail: enrico.scarpella@ualberta.ca

\# Note: These authors contributed equally.

Supplementary Material for this paper (one figure and one table) is available at: http://dx.doi.org/10.1387/ijdb.093006jg 
transcription factor MONOPEROS (MP) (Donner et al., 2009; Hardtke and Berleth, 1998; Scarpella et al., 2006; Wenzel et al., 2007). Decay of PIN1 and MP expression and associated relapse to ground state occur in some of the cells, and domains of PIN1 and MP expression are eventually restricted to individual files of cells that will elongate into procambial cells (Donner et al., 2009; Scarpella et al., 2006; Wenzel et al., 2007).

While onset of PIN1 and MP expression marks an unstable and reversible state in formation of leaf vascular strands (or 'veins'), lines of PIN1 and MP-expressing ground cells that are stabilized towards procambial fate activate expression of the class III HOMEODOMAIN-LEUCINE ZIPPER (HD-ZIP III) gene ATHB8 (Baima et al., 1995; Donner et al., 2009; Kang and Dengler, 2004; Sawchuk et al., 2007; Scarpella et al., 2004). Initiation of ATHB8 expression is directly controlled by MP (Donner et al., 2009), and identifies acquisition of a critical and typically irreversible 'preprocambial' cell state that accurately predicts sites of vascular differentiation (Alonso-Peral et al., 2006; Candela et al., 2001; Carland and Nelson, 2004; Cnops et al., 2006; Donner et al., 2009; Kang and Dengler, 2004; Koizumi et al., 2000; Petricka and Nelson, 2007; Pineau et al., 2005; Sawchuk et al., 2007, 2008; Scarpella et al., 2004, 2006). A view of the transcriptional landscape of cells at preprocambial stages would be particularly valuable as it might provide insight into the molecular pathways underlying vein formation. However, very few genes have been identified whose expression is initiated at stages prior to procambium formation [e.g., (Alonso-Peral et al., 2006; Baima et al., 1995; Carland and Nelson, 2009; Hardtke and Berleth, 1998; Kang and Dengler, 2004; Konishi and Yanagisawa, 2007; Scarpella et al., 2004;, 2006; Steinmann et al., 1999; Wenzel et al., 2007)].

In this study, we searched for gene expression profiles associated with early stages of vascular development in Arabidopsis leaves. We reasoned that at least some of the genes expressed during vein formation may be expected to display similar vascularbiased expression in other organs. We extracted root vascularspecific gene expression profiles from available whole-genome transcript accumulation data sets (Birnbaum et al., 2003), and converged on genes encoding transcription factors of the plant-specific DOF (DNNA-BINDING WITH ONNE ZINC FINGER) family (Lijavetzky et al., 2003; Yanagisawa, 2002) because of the correlation between their molecular diversification and the functional differentiation of the plant body into physiologically distinct organs during evolution (Shigyo et al., 2007). Our findings suggest that expression of three DOFgenes can be assigned to stages of preprocambial development that overlap with acquisition of the $A T H B 8$ cell state. Under both undisturbed and pharmacologically perturbed leaf development, broad domains of DOFgene expression become restricted to sites of vein formation, suggesting that dynamics of DOFexpression define reproducible cell states in preprocambial development. Our results assist in the mo- lecular characterization of cell identity at morphologically indistinguishable stages of vein formation.

\section{Results}

All genes whose expression has previously been assigned to early stages of vascular development in the leaf have also been reported to be expressed in root vascular cells [e.g., (AlonsoPeral et al., 2006; Baima et al., 1995; Carland and Nelson, 2009; Hardtke and Berleth, 1998; Kang and Dengler, 2004; Konishi and Yanagisawa, 2007; Scarpella et al., 2004; Scarpella et al., 2006; Steinmann et al., 1999; Wenzel et al., 2007)]. Therefore, to identify new preprocambial gene expression profiles, we interrogated an available global gene expression map of the Arabidopsis root (Birnbaum et al., 2003) to extract root vascular-specific gene expression datasets. We focused on genes encoding members of the DOF family of plant-specific transcription factors because their evolutionary diversification is associated with the compartmentalization of the plant body into separate organs (Shigyo etal., 2007). We found that nine of the 36 DOFgenes in Arabidopsis (Lijavetzky et al., 2003; Yanagisawa, 2002) displayed a strong expression bias for root vascular cells (Fig. 1). Detailed expression data for five of these nine DOFgenes are already available and support their vascular-specific expression in roots and other organs (Gualberti et al., 2002; Skirycz et al., 2006; Ward et al., 2005; Zhao et al., 2005), suggesting that preselecting vascular gene expression profiles based on root expression patterns from whole-genome microarray datasets may be an effective criterion. Here we investigated leaf expression of the remaining four DOF genes 2.1, 3.1, 4.6 and 5.3.

\section{Expression of DOF genes in seedling organs}

Because the upstream noncoding region is sufficient to recapitulate the endogenous transcript accumulation pattern in $80 \%$ of the cases for 44 Arabidopsis transcription factors (Lee et al., 2006), to visualize DOFgene expression patterns at high resolution, we employed transcriptional reporter gene fusions with an

\begin{tabular}{|c|c|c|c|c|c|c|}
\hline Gene & Locus & Root cap & Epidermis & Cortex & Endodermis & Stele \\
\hline DOF1.1 & At1g07640 & $16 \pm 7.8$ & $18 \pm 8.9$ & $33 \pm 16.5$ & $42 \pm 20.8$ & $114 \pm 56.5$ \\
\hline DOF2.1 & At2g28510 & $22 \pm 4.3$ & $17 \pm 3.4$ & $69 \pm 13.9$ & $76 \pm 15.2$ & $123 \pm 24.7$ \\
\hline DOF2.2 & At2g28810 & $28 \pm 7.1$ & $18 \pm 4.6$ & $35 \pm 8.7$ & $35 \pm 8.9$ & $104.3 \pm 26.3$ \\
\hline DOF2.5 & At2g46590 & $11 \pm 5.7$ & $8 \pm 4.4$ & $29 \pm 15.7$ & $28 \pm 14.8$ & $60 \pm 32.4$ \\
\hline DOF3.1 & At3g21270 & $35 \pm 12.1$ & $28 \pm 9.7$ & $39 \pm 13.6$ & $41 \pm 14.4$ & $121 \pm 41.9$ \\
\hline DOF3.6 & At3g55370 & $2 \pm 1.4$ & $4 \pm 3.3$ & $9 \pm 7.0$ & $6 \pm 4.3$ & $36 \pm 26.5$ \\
\hline DOF3.7 & At3g61850 & $26 \pm 12.2$ & $19 \pm 8.6$ & $74 \pm 34.4$ & $69 \pm 32.2$ & $289 \pm 134.2$ \\
\hline DOF4.6 & At4g24060 & $15 \pm 5.4$ & $14 \pm 4.9$ & $78 \pm 27.5$ & $67 \pm 23.8$ & $170 \pm 59.9$ \\
\hline DOF5.3 & At5g60200 & $3 \pm 0.7$ & $6 \pm 1.5$ & $26 \pm 6.2$ & $29 \pm 7.1$ & $168 \pm 40.7$ \\
\hline
\end{tabular}

Fig. 1. Chart of DOF expression in root tissues. Heat map showing levels of DOF expression in different tissues of the Arabidopsis root. Data compiled in (Birnbaum et al., 2003) were interrogated with the AGl codes of the 36 DOF genes in Arabidopsis (Lijavetzky et al., 2003; Yanagisawa, 2002) through the Arabidopsis eFP browser tool (Winter et al., 2007), and profiles of the nine genes with biased expression in vascular cells ('stele') are represented. Values represent mean \pm SD of gene expression levels at development stages I-III [see (Birnbaumet al., 2003) for more details]. To visualize changes in gene expression, a light-to-dark blue look-up table (LUT) with 25-percentile color steps was adopted, in which darker shades represent progressively stronger expression. 



Fig. 2 (Left). DOF expression in seedling organs. Top right, gene identity. Bottom left, fraction of samples showing the displayed features. (A-H) Wide-field epifluorescence microscopy. An LUT (displayed in A) in which black was used to encode global background, blue to encode local background, and cyan, green, yellow, orange, and red to encode increasing signal intensities (Sawchuk et al., 2008) was applied to eight-bit grayscaled images to generate color-coded images. (A-D) Root tips. (E-H) Leaves (abaxial view). (A) See Supplementary Figure S1 for additional expression patterns and their frequencies. Scale bars, $50 \mu \mathrm{m}$

Fig. 3 (Right). DOFexpression in first leaf development. Top right, leaf primordium age in days after germination (DAG). Bottom left, fraction of samples showing the displayed features. (A,E,I,M, $\mathbf{Q})$ Lateral view (adaxial side to the right). (B-D,F-H,J-L,N-P,R-T) Abaxial view. (A-D) Illustrations depicting the spatiotemporal course of vein formation in Arabidopsis first leaf development as inferred from published works (see text for references), and definition of terms used in this study; see also Materials and methods. (A-C) Whole leaves. (D) Detail of the lower-right region of a mature leaf. Cyan, preprocambial stages; blue, procambial stages; purple, mature veins; $h v$, higher-order vein; 11,12 and 13 , first, second and third loop, respectively; mv, midvein. (E-T) Overlay of confocal laser scanning and differential interference contrast microscopy images. (E-H) White,

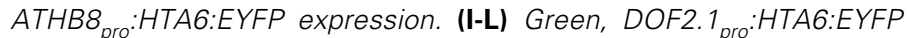
expression. (M-P) Magenta, DOF4.6 pro $^{\text {:HTA6:EYFP expression. (Q-T) }}$ Yellow, DOF5.3 $3_{\text {pro: }}$ GFP4er expression. Scale bars: E,I,M,Q, $10 \mu \mathrm{m}$; $F, J, N, R, 20 \mu \mathrm{m} ; G, K, O, S, 50 \mu m ; H, L, P, T, 75 \mu \mathrm{m}$.

endoplasmic reticulum-targeted GFP (mGFP4er) (Haseloff et al., 1997) or a nuclear localized YFP (HTA6:EYFP) (Zhang et al., 2005).

We first asked whether DOFpromoter activity could recapitulate the root vascular-specific expression suggested by transcript profiling (Birnbaum et al., 2003). To address this question, we

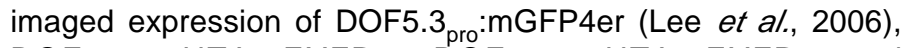
DOF2. $1_{\text {pro: }}$ :HTA6:EYFP, DOF3.1 ${ }_{\text {pro }}:$ HTA6:EYFP and DOF4.6 ${ }_{\text {pro }}$ :HTA6:EYFP in the root of seedlings 4 days after germination (DAG). While transcriptional fusions of DOF2.1, DOF4.6 and DOF5.3 were expressed in root vascular cells, DOF3.1 $1_{\text {pro: }}$ HTA6:EYFP fluorescence was confined to the quiescent centre region (Fig. 2 A-D), suggesting that, at least in the root, patterns of DOF3.1 promoter activity may not reflect the gene's transcriptional profile.

We next asked whether DOFgene expression was associated with sites of vascular strand formation in the leaf. To address this question, we visualized expression of DOF2.1 pro:HTA6:EYFP, DOF3. $1_{\text {pro }}$ :HTA6:EYFP, DOF 4.6 pro $_{\text {HTA6:EYFP and }}$
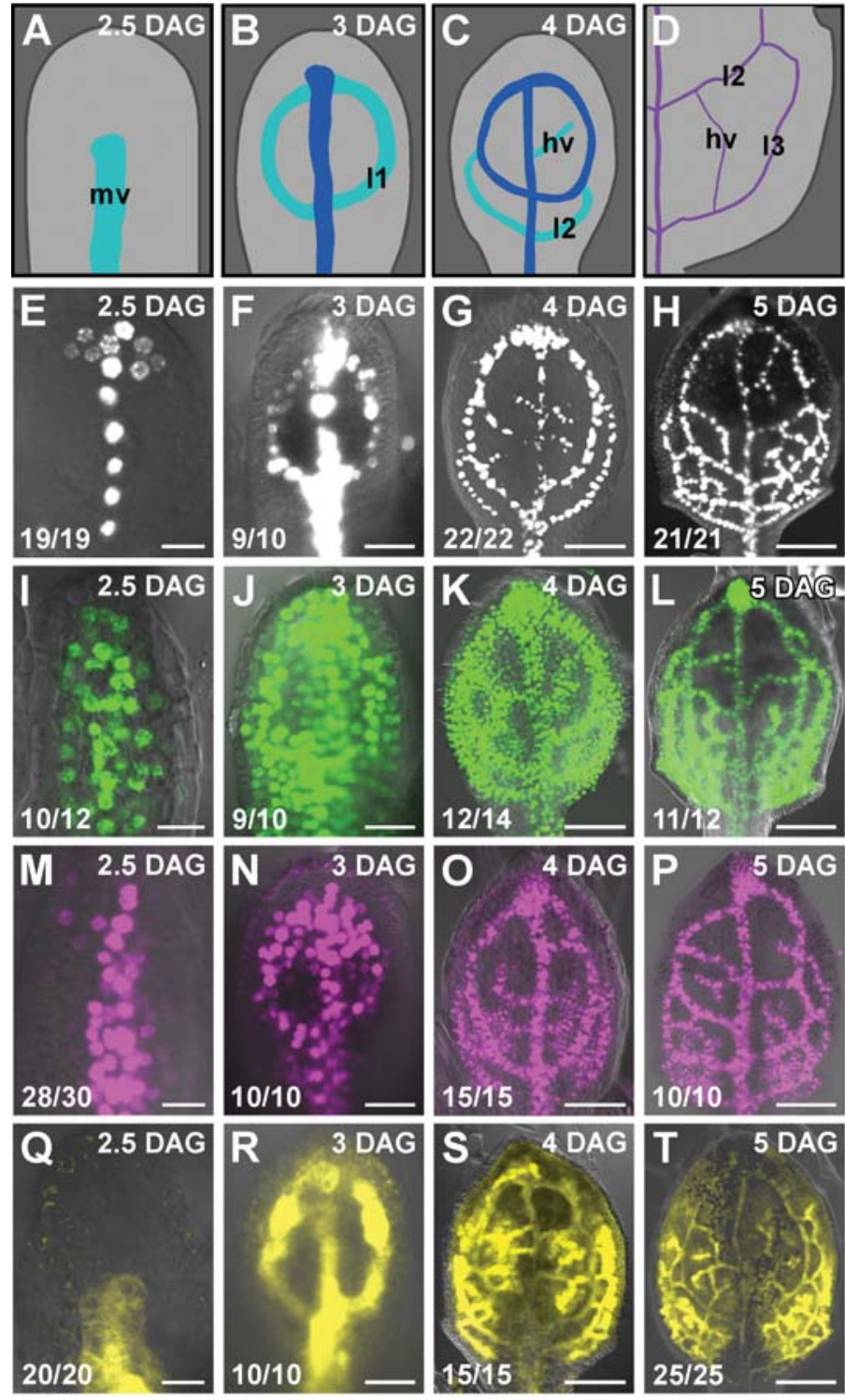

DOF5.3 $3_{\text {pro }}$ :mGFP4er in 4-DAG first leaves as their venation is predominantly preprocambial and procambial (Donner et al., 2009; Sawchuk et al., 2007). Expression of fusions of DOF2.1, DOF4.6 and DOF5.3was activated in correlation to zones of vein emergence, while DOF3.1 pro $_{\text {HTA6:EYFP signals were restricted }}$ to the leaf tip and the most basal portion of the central midvein (Fig. $2 \mathrm{E}-\mathrm{H}$ ), suggesting that the DOF3. 1 transcriptional fusion is not appropriate for marking early stages of vein formation. Therefore, successive analyses were performed on DOF2.1 $1_{\text {pro }}:$ HTA6:EYFP, DOF4.6 $6_{\text {pro }}:$ HTA6:EYFP and DOF5.3 $3_{\text {pro }}:$ mGFP4er lines.

\section{DOF expression during leaf development}

Expression of DOF2.1, DOF4.6 and DOF5.3 all seemed to label early stages of vein formation (Fig. 2 E,G,H). However, patterns of initiation, progression and termination, or persistence, of expression could be remarkably different, even for genes that are expressed similarly at any single stage of leaf development. Therefore, to visualize dynamics of DOFexpression over time, we 

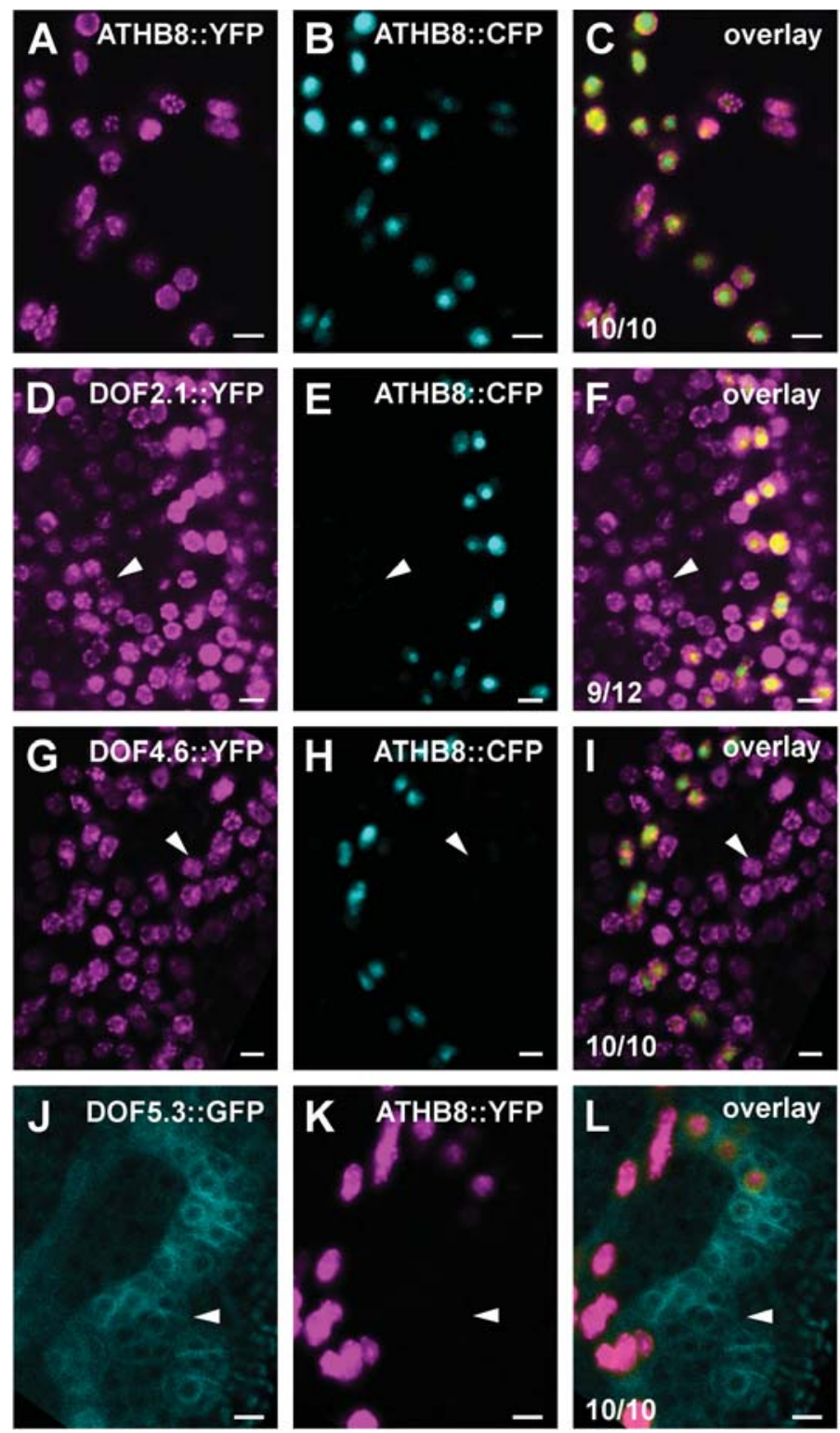

monitored activity of DOF2.1 pro:HTA6:EYFP, DOF4.6 pro $_{\text {:HTA6:EYFP and DOF5.3 }}$ pro:mGFP4er, and of the reference preprocambial marker ATHB8 $8_{\text {pro }}$ :HTA6:EYFP (Donner et al., 2009; Sawchuk et al., 2007) in first leaf primordia at 2.5, 3, 4, and 5 DAG. In Arabidopsis, veins of subsequent orders become recognizable progressively later in the same area of the developing leaf primordium, and veins of the same order appear in a tip-tobase sequence during leaf development (Candela et al., 1999; Kang and Dengler, 2002, 2004; Kinsman and Pyke, 1998; Mattsson et al., 1999; Scarpella et al., 2004; Sieburth, 1999; Steynen and Schultz, 2003; Telfer and Poethig, 1994). The illustrations in Figure 3 (Fig. 3 A-D) schematically depict the temporal sequence of vascular development events in Arabidopsis leaf primordia, and define the stages and terminology to which we refer throughout this study (for additional details, see Materials and methods).

At 2.5 DAG, expression of all transcriptional fusions was visible in the central region of the leaf primordium (Fig. $3 \mathrm{E}, \mathrm{I}, \mathrm{M}, \mathrm{Q}$ ). While ATHB8 $_{\text {pro }}$ :HTA6:EYFP signals were confined to a single cell file,
Fig. 4. Vein stage-specific DOFexpression. Top right, marker identifier. Bottom left, fraction of samples showing the displayed features. (A-L) 4 DAG leaves, abaxial view. Confocal laser scanning microscopy. $(\mathbf{A}, \mathbf{C}, \mathbf{K}, \mathbf{L})$ Magenta, ATHB8 ${ }_{\text {pro }}$ :HTA6:EYFP expression. (B,C,E, $\left.\mathbf{F}, \mathbf{H}, \mathbf{I}\right)$ Cyan,

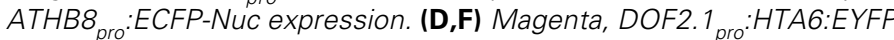
expression. (G,I) Magenta, DOF4.6 :HTA6:EYFPexpression. $\mathbf{( J , L ) ~ C y a n , ~}$ DOF5.3 $3_{\text {pro: }}$ GFP4er expression. (C,F,I,L) Images color-coded with a dual-channel LUT from cyan to magenta through green, yellow, and red (Demandolx and Davoust, 1997). Fluorescence in each detection channel was displayed in either cyan or magenta. Single-fluorophore images were then merged using a differential operator. As a result, preponderance of cyan signal over colocalized magenta signal is encoded in green, opposite in red, and colocalized cyan and magenta signals of equal intensity in yellow. Arrowheads indicate domains of DOF promoter activity lacking expression of ATHB8 fusions. Scale bars, $5 \mu \mathrm{m}$.

expression of DOF fusions occupied wider territories, which in DOF5.3 ${ }_{\text {pro }}$ :mGFP4er comprised two adjacent columns of cells and in DOF2. $1_{\text {pro }}$ :HTA6:EYFP encompassed nearly all subepidermal cells. Expression of fusions of $A T H B 8, D O F 2.1$ and DOF4.6 was additionally detected at the tip of the 2.5-DAG primordium. At 3 DAG, all fusions were strongly expressed at sites of midvein and first loop appearance; however, DOF promoters were active in broader domains than ATHB8 $8_{\text {pro }}$ :HTA6:EYFP, with only slightly expanded fields of DOF5.3 $3_{\text {pro }}$ :mGFP4er expression at the apical side of the developing first loops and weak DOF2. $1_{\text {pro }}$ :HTA6:EYFP fluorescence in almost all subepidermal cells (Fig. 3 F,J,N,R). At $4 \mathrm{DAG}$, activity of all fusions marked zones of formation of midvein, first and second loops, and higher-order veins, even though levels of midvein-associated DOF5.3 pro:mGFP4er expression were considerably lower than those detectable in all other veins (Fig. 3 $\mathrm{G}, \mathrm{K}, \mathrm{O}, \mathrm{S})$. Further, while domains of $A T H B 8$ promoter activity were equally narrow in all developing veins, expression of DOFfusions in prospective second loops and higher-order veins pervaded larger fields of cells than in the emerging midvein and first loops. Finally, at 5 DAG, all promoters directed expression in developing midvein, first, second and third loops, and in higher-order veins (Fig. $3 \mathrm{H}, \mathrm{L}, \mathrm{P}, \mathrm{T}$ ), but fields of DOF fusion activity were wider in veins emerging in basal areas of the leaf, and DOF5.3 ${ }_{\text {pro }}$ :mGFP4er expression had subsided in midvein and first loops.

In summary, expression of all DOFgenes seemed to be tightly associated with regions of vascular strand formation throughout leaf development.

\section{Stage-specific DOF expression in vein formation}

Comparison between $D O F$ and $A T H B 8$ expression profiles during leaf development (Fig . 3) suggests that expression of $D O F$ genes is initiated as early as that of $A T H B 8$, and that therefore $D O F$ expression could be assigned to preprocambial stages of vein formation. An unambiguous criterion to test such a hypothesis, however, would be to visualize expression of individual DOFgenes and $A T H B 8$ within the same sample. We therefore tested the degree of colocalization between DOF2.1 $1_{\text {pro }}$ :HTA6:EYFP and ATHB $_{\text {pro: }}$ ECFP-Nuc (Sawchuk et al., 2008), between DOF4.6 $6_{\text {pro }}$ HTA6:EYFP and ATHB ${ }_{\text {pro }}$ :ECFP-Nuc, and between

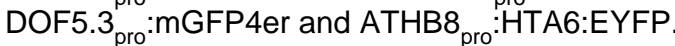

Covisualization of DOFtranscriptional fusion signals and inception of $A T H B 8$ promoter activity showed overlapping expression of the fluorescent reporters (Fig. $4 \mathrm{D}-\mathrm{L}$ ), suggesting that DOF expression is initiated at preprocambial stages. However, at onset of 
Fig. 5. DOF expression in auxin transport-inhibited first leaves. Top right, leaf age in DAG. Bottom left, fraction of samples showing the displayed features. (A-L) Leaves (abaxial view) developing in the presence of 2.5 $\mu$ M NPA. Overlay of confocal laser scanning and differential interference contrast microscopy images. (A-C) White, ATHB8 pro: $_{\text {HTA6:EYFP expression. (D-F) Green, DOF2.1 }}$ pro:HTA6:EYFP expression. (G-I) Magenta, DOF4.6 pro:HTA6:EYFP expression. (J-L) YelIow, DOF5.3 $3_{\text {pro: }}$ GFP4er expression. Note how the size of areas devoid of DOF expression (arrowheads) expands during leaf development, suggesting progressive restriction of DOF expression domains. Scale bars: $A, D, G, J, 20 \mu m ; B, E, H, K, 50 \mu m ; C, F, I, L, 75 \mu m$.

ATHB8 promoter activity, expression domains of DOF fusions were always wider than those of $A T H B 8$. Further, domains of $A T H B 8$ fusion expression were visible that did not extend throughout the full length of fields of DOFpromoter activity (Fig. 4 D-F, JL). Finally, we observed entire expression domains of DOFfusions that were totally devoid of $A T H B 8$ promoter activity (Fig. $4 \mathrm{G}-\mathrm{I}$ ).

\section{DOF expression in auxin transport-inhibited leaves}

We finally asked whether expression of DOFgenes remained associated with zones of leaf vascular strand formation upon experimental interference with vein patterning. Auxin transport has been shown to define sites of vein appearance in developing leaf primordia (Mattsson et al., 1999; Scarpella et al., 2006; Sieburth, 1999). Therefore, we grew seedlings harboring the DOF and $A T H B 8$ transcriptional fusions in the presence of the auxin transport inhibitor 1-N-naphthylphthalamic acid (NPA) and imaged fluorescent protein expression in first leaves at 3, 4, and 5 DAG.

Leaves of plants germinated and grown in the presence of auxin transport inhibitors are characterized by a number of distinct anomalies in vascular organization; most conspicuously, great numbers of broad vein loops fuse along the entire margin of the leaf, to give rise to a wide zone of vascular differentiation, and extend parallel at the centre of the leaf, to give rise to a laterally expanded midvein (Mattsson et al., 1999; Sieburth, 1999). As shown in Figure 5, domains of ATHB8 ${ }_{\text {pro }}$ :HTA6:EYFP expression retained their characteristically slender shape throughout development of auxin transport-inhibited leaves (Fig. 5 A-C). Expression of DOF transcriptional fusions, on the other hand, appeared extremely expanded in leaves with reduced auxin transport, such that DOFpromoters were active in nearly all subepidermal cells at 3 DAG (Fig. 5 D,G,J). Nevertheless, quasi-ubiquitous expression of $D O F$ fusions became resolved into more discrete domains, which were already visible in the apical half of 4-DAG leaves (Fig. $5 \mathrm{E}, \mathrm{H}, \mathrm{K}$ ) and became further restricted in leaves at $5 \mathrm{DAG}$ (Fig. 5 $\mathrm{F}, \mathrm{I}, \mathrm{L}$ ).

In conclusion, the association between DOF expression domains and regions of vein formation observed under undisturbed conditions persisted in auxin transport-inhibited leaves, suggesting non-circumstantial correlation between zones of DOFexpression and sites of vein emergence.

\section{Discussion}

The molecular details of the mechanisms controlling the recruitment of ground cells in the leaf towards procambium formation are largely unknown. Available evidence, however, suggests that the selection process terminates with emergence of files of ground
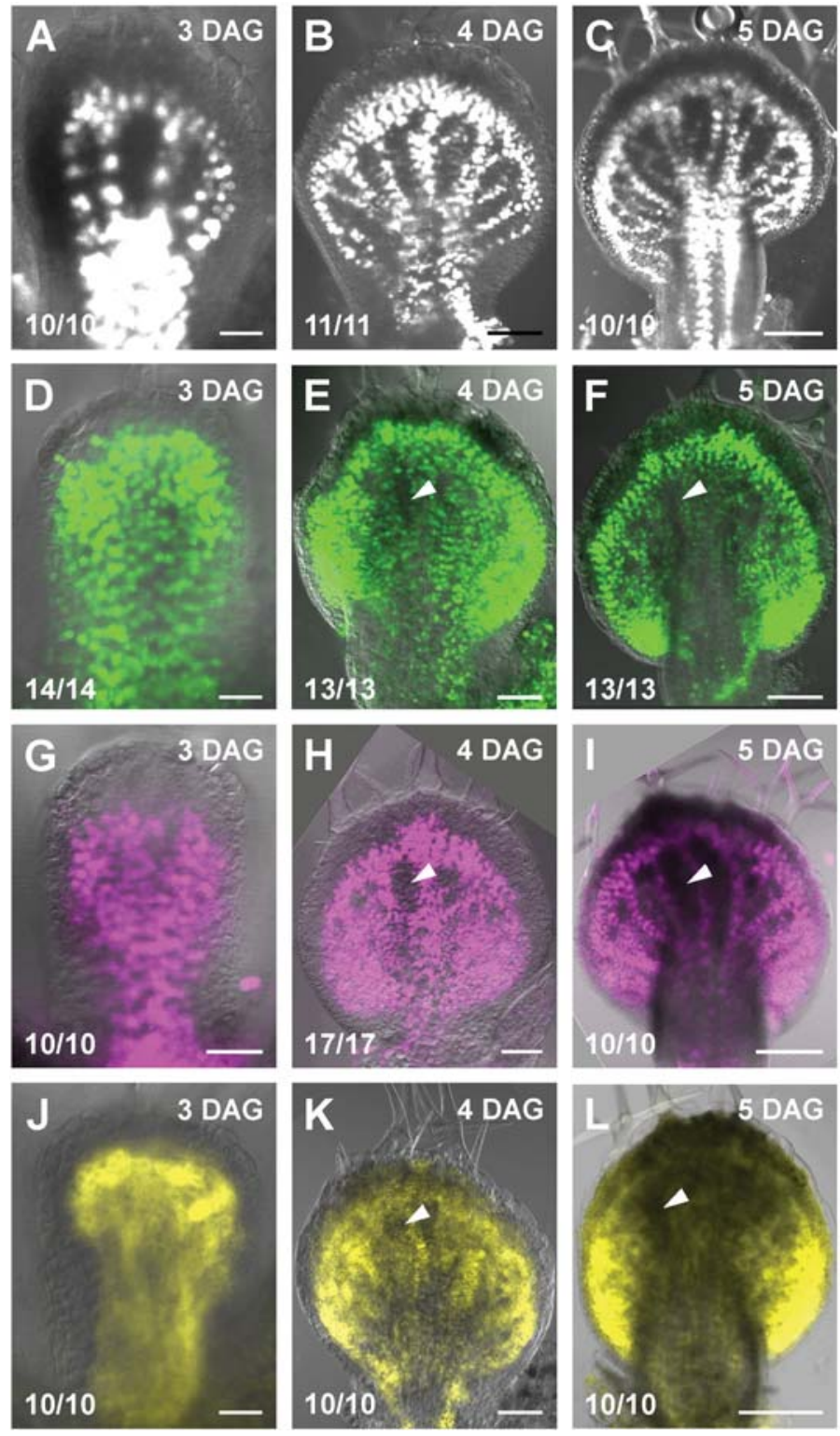

cells that have activated expression of the $H D$-ZIP ///gene $A T H B 8$ and that will successively elongate into procambial cells (AlonsoPeral et al., 2006; Candela et al., 2001; Carland and Nelson, 2004; Cnops et al., 2006; Donner et al., 2009; Kang and Dengler, 2004; Koizumi et al., 2000; Petricka and Nelson, 2007; Sawchuk et al., 2007, 2008; Scarpella et al., 2004, 2006). Therefore, the events preceding acquisition of the $A T H B 8$ preprocambial cell state are crucial for vein formation.

In this study, we have sought gene expression profiles that were initiated at preprocambial stages. We have found that expression of DOF2.1, DOF4.6 and DOF5.3, which encode members of the DOF family of plant-specific transcription factors (Lijavetzky et al., 2003; Yanagisawa, 2002), reproducibly identifies morphologically inconspicuous cell states in the process that culminates into onset of $A T H B 8$ expression.

\section{Cell state transitions in vein formation}

Transcription of DOF2.1,DOF4.6 and DOF5.3 could be con- 
trolled by regions other than the upstream noncoding sequences used here to monitor their expression, and abundance of transcripts of DOF2. 1, DOF4.6and DOF5.3could be regulated at the post-transcriptional level. However, our results are in good agreement with expression profiles extracted from publicly accessible large-scale microarray data sets (Birnbaum et al., 2003; Schmid et al., 2005; Winter et al., 2007), suggesting that expression patterns of DOF2.1, DOF4.6 and DOF5.3 can be accurately visualized by transcriptional fusions.

During leaf development, DOF2. 1, DOF4.6 and DOF5.3were expressed in seemingly overlapping subepidermal domains and with amazingly comparable dynamics. At early stages of leaf development, very low levels of DOF2. 1 expression embraced all ground cells; within these fields, however, broad domains of maximum expression of DOF2. 1 were distinguishable that became associated with sites of vein emergence, as identified by ATHB8 expression. During subepidermal tissue ontogeny, weak DOF2. 1expression became extinguished from subsets of ground cells, leaving only the intense vein-associated expression domains. Expression of DOF4.6 and DOF5.3 was initiated in wide domains that seemed to coincide with peaks of DOF2.1 expression, but their expression never incorporated all surrounding ground cells. Expression of DOF2. 1 and DOF4.6 was sustained at all stages of vein formation, while that of DOF5.3 became terminated during procambium differentiation. Areas of DOF expression overlapped with sites of initiation of $A T H B 8$ expression, suggesting that DOF2.1,DOF4.6 and DOF5.3 are expressed at preprocambial stages. However, that discrete $D O F$ expression domains were visible that were partially or completely free of $A T H B 8$ expression may suggest that expression of DOF2. 1 , DOF4.6 and DOF5.3 is initiated prior to acquisition of the ATHB8 preprocambial cell state. Alternatively, or in addition, this observation may point to transient appearance of $D O F$ expression in cells that will never activate expression of $A T H B 8$.

If congruence between expression of DOF2.1, DOF4.6 and $D O F 5.3$ and sites of vein formation is more than a coincidence, one would expect to observe such association even under conditions of manipulated leaf vascular patterning. Expression of DOF genes in leaves with reduced auxin transport, which dramatically changes the shape of vein networks (Mattsson et al., 1999; Sieburth, 1999), retained dynamics comparable to those observed under undisturbed development. Furthermore, all aspects of DOFexpression, including onset, intensity, decline, relation to ATHB8 expression and association with vein-forming cells under all experimental conditions proved to be highly reproducible. We therefore suggest that expression of DOF2. 1, DOF4.6and DOF5.3 identifies regularly recurring steps in preprocambial development.

Unlike $A T H B 8, D O F$ expression was always initiated in wide domains, and $A T H B 8$ expression appeared within broad DOF expression domains. Furthermore, initially-wide fields of $D O F$ expression became laterally confined over time, while ATHB8 expression domains are always narrow at inception and progress longitudinally during vein formation. In this respect, expression of DOF2. 1, DOF4.6 and DOF5.3resembles that of genes that have been functionally implicated in selection of $A T H B 8$-expressing preprocambial cells [e.g., (Alonso-Peral et al., 2006; Candela et al., 2001; Carland and Nelson, 2004; Donner et al., 2009; Hardtke and Berleth, 1998; Petricka and Nelson, 2007; Sawa et al., 2005;
Sawchuk et al., 2007; Scarpella et al., 2006)]. However, DOF2. 1 , DOF4.6 and DOF5.3 are not expected to be directly involved in this process because preprocambial expression of $A T H B 8$ is under the immediate control of MP through a noncanonical auxin response element located in the ATHB8promoter (Donner et al., 2009).

\section{Vascular expression profiles of DOF genes}

The DOFgenes whose leaf expression was investigated here were selected because of their biased expression for root vascular cells in an Arabidopsis transcription map (Birnbaum et al., 2003), and because their leaf expression had not previously been reported. Root vascular expression was recapitulated by patterns of promoter activity for three of the four DOFgenes, and all of the three root vascular-specific promoters were also active at early stages of vascular strand formation in the leaf. Preselecting veinassociated gene expression profiles based on root expression patterns proved to be a valuable strategy, but this does not exclude the possibility that other DOFgenes may be expressed in leaf vascular strands. Indeed, DOF5.8, which is negligibly expressed in root microarray datasets, displays prominent veinassociated expression (Konishi and Yanagisawa, 2007). Tissuespecific expression patterns are available for 13 of the 36 Arabidopsis DOF genes (Fornara et al., 2009; Gardner et al., 2009; Gualberti et al., 2002; Imaizumi et al., 2005; Konishi and Yanagisawa, 2007; Skirycz et al., 2006, 2007, 2008; Ward et al., 2005). These 13 genes sample the diversity of the DOFfamily, yet all of them appear to be expressed in vascular strands. While it will be interesting to understand the significance of the association between the expression of at least a large fraction of DOFgenes and vascular cells, our study already contributes to the characterization of a largely unexplored class of plant-specific transcription factors.

\section{Materials and Methods}

\section{Terminology}

We apply the generic term 'subepidermal' to all positions of the leaf beneath the epidermis. We refer to 'ground cells' as polygonal, isodiametric, subepidermal cells of the leaf. We use the terms 'procambial' and 'procambium' to indicate morphologically identifiable vascular cell precursors. We designate as 'preprocambial' all stages of vein development prior to procambium formation.

\section{Vector construction}

To generate DOFtranscriptional fusions, the genes' entire noncoding regions were amplified from Arabidopsis (Arabidopsis thaliana) ecotype Col-0 genomic DNA using Finnzymes Phusion high-fidelity DNA polymerase (New England Biolabs Inc., Ipswich, MA, USA) and gene-specific primers (Supplementary Table S1), integrated into pDONR221 (Invitrogen, Carlsbad, CA, USA) with BP clonase II (Invitrogen), sequencechecked, and recombined into the Gateway-adapted pFYTAG binary vector, which contains a translational fusion between the coding region of histone 2A (HTA6; At5g59870) and that of the enhanced YFP (EYFP) (Zhang et al., 2005), using LR clonase II (Invitrogen).

\section{Plant material and growth conditions}

The origins of the ATHB8 $8_{\text {pro }}:$ HTA6:EYFP, DOF5.3 $3_{\text {pro }}$ :mGFP4er and

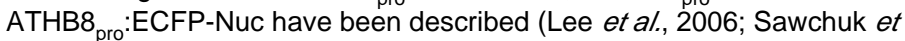
al., 2007, 2008;). Seeds were sterilized and germinated, and seedlings and plants were grown, transformed and selected as described (Sawchuk et al., 
2007, 2008). For DOF2.1 $1_{\text {pro }}:$ HTA6:EYFP, DOF3.1 pro:HTA6:EYFP and DOF4.6 $6_{\text {pro }}:$ HTA6:EYFP, the progeny of 11 to 18 independent transgenic lines were inspected to identify the most representative expression pattern. Successive expression analysis was performed on the progeny of at least four lines per construct, which were selected because of strong YFP expression that was emblematic of the expression profile observed across the entire series of transgenic lines and that resulted from single insertion of the transgene. For DOF5.3 ${ }_{\text {pro }}$ :mGFP4er, expression analysis was performed on the progeny of two lines per construct (JYB818.3, ABRC stock number: CS70640; JYB821.1, ABRC stock number: CS70641). In genetic crosses, the progeny of at least two independent lines per construct were examined. For auxin transport inhibition, seeds were germinated on growth medium supplemented with $2.5 \mu \mathrm{MNPA}$ (Chem Service Inc., West Chester, USA). We define 'days after germination' (DAG) as days following exposure of imbibed seeds to light.

\section{Microscopy and image processing}

Dissected seedling organs were mounted and imaged as described (Donner etal., 2009; Sawchuk etal., 2007, 2008). Brightness and contrast were adjusted through linear stretching of the histogram in ImageJ (National Institutes of Health, http://rsb.info.nih.gov/ij). Signal levels and colocalization were visualized as described (Sawchuk et al., 2008).

\section{Acknowledgements}

We would like to thank the Arabidopsis Biological Resource Center and David Galbraith for kindly providing seeds and plasmids; and Tyler Donner and Megan Sawchuk for merciless criticism. This work was supported by a Discovery Grant of the Natura/ Sciences and Engineering Research Council of Canada (NSERC), by an Alberta Ingenuity (Al) New Faculty Grant and by the Canada Research Chairs Program.

\section{References}

ALONSO-PERAL, M.M., CANDELA, H., DEL POZO, J.C., MARTINEZ-LABORDA, A., PONCE, M.R. and MICOL, J.L. (2006). The HVE/CAND1 gene is required for the early patterning of leaf venation in Arabidopsis. Development 133: 37553766.

BAIMA, S., NOBILI, F., SESSA, G., LUCCHETTI, S., RUBERTI, I. and MORELLI, G. (1995). The expression of the Athb-8 homeobox gene is restricted to provascular cells in Arabidopsis thaliana. Development 121: 4171-4182.

BERLETH, T., MATTSSON, J. and HARDTKE, C.S. (2000). Vascular continuity and auxin signals. Trends Plant Sci5: 387-93.

BERLETH, T. and SACHS, T. (2001). Plant morphogenesis: long-distance coordination and local patterning. Curr Opin Plant Bio/4: 57-62.

BIRNBAUM, K., SHASHA, D.E., WANG, J.Y., JUNG, J.W., LAMBERT, G.M., GALBRAITH, D.W. and BENFEY, P.N. (2003). A gene expression map of the Arabidopsis root. Science 302: 1956-1960.

CANDELA, H., MARTINEZ-LABORDA, H., MICOL J.L. (2001). Interactions between venation pattern formation genes in Arabidopsis thaliana. Int J Dev Biol 45: S35-S36.

CARLAND, F. and NELSON, T. (2009). CVP2-and CVL1-mediated phosphoinositide signaling as a regulator of the ARF GAP SFC/VAN3 in establishment of foliar vein patterns. Plant J59: 895-907.

CARLAND, F.M. and NELSON, T. (2004). Cotyledon vascular pattern2-mediated inositol $(1,4,5)$ triphosphate signal transduction is essential for closed venation patterns of Arabidopsis foliar organs. Plant Cel/16: 1263-1275.

CNOPS, G., NEYT, P., RAES, J., PETRARULO, M., NELISSEN, H., MALENICA, N., LUSCHNIG, C., TIETZ, O., DITENGOU, F., PALME, K. et al. (2006). The TORNADO1 and TORNADO2 genes function in several patterning processes during early leaf development in Arabidopsis thaliana. Plant Cel/18: 852-866.

DEMANDOLX, D. and DAVOUST, J. (1997). Multicolour analysis and local image correlation in confocal microscopy. J Microsc 185: 21-36.

DONNER, T.J., SHERR, I. and SCARPELLA, E. (2009). Regulation of preprocambial cell state acquisition by auxin signaling in Arabidopsis leaves. Development 136: 3235-3246.
ESAU, K. (1943). Origin and development of primary vascular tissues in plants. Bot Rev 9: 125-206.

ESAU, K. (1965). Plant anatomy. John Wiley and Sons, New York/London.

FORNARA, F., PANIGRAHI, K.C., GISSOT, L., SAUERBRUNN, N., RUHL, M., JARILLO, J.A. and COUPLAND, G. (2009). Arabidopsis DOF transcription factors act redundantly to reduce CONSTANS expression and are essential for a photoperiodic flowering response. Dev Cel/ 17: 75-86.

FOSTER, A.S. (1936). Leaf differentiation in Angiosperms. Bot Rev2: 349-372.

FOSTER, A.S. (1952). Foliar venation in Angiosperms from an ontogenetic standpoint. Am J Bot 39: 752-766.

GARDNER, M.J., BAKER, A.J., ASSIE, J.M., POETHIG, R.S., HASELOFF, J.P. and WEBB, A.A. (2009). GAL4 GFP enhancer trap lines for analysis of stomatal guard cell development and gene expression. J Exp Bot 60: 213-226.

GUALBERTI, G., PAPI, M., BELLUCCI, L., RICCI, I., BOUCHEZ, D., CAMILLERI, C., COSTANTINO, P. and VITTORIOSO, P. (2002). Mutations in the Dof zinc finger genes DAG2 and DAG1 influence with opposite effects the germination of Arabidopsis seeds. Plant Cell 14: 1253-1263.

HARDTKE, C.S. and BERLETH, T. (1998). The Arabidopsis gene MONOPTEROS encodes a transcription factor mediating embryo axis formation and vascular development. EMBO J17: 1405-1411.

HASELOFF, J., SIEMERING, K.R., PRASHER, D.C. and HODGE, S. (1997). Removal of a cryptic intron and subcellular localization of green fluorescent protein are required to mark transgenic Arabidopsis plants brightly. Proc Nat/ Acad Sci USA 94: 2122-2127.

IMAIZUMI, T., SCHULTZ, T.F., HARMON, F.G., HO, L.A. and KAY, S.A. (2005) FKF1 F-box protein mediates cyclic degradation of a repressor of CONSTANS in Arabidopsis. Science 309: 293-297.

KANG, J. and DENGLER, N. (2004). Vein pattern development in adult leaves of Arabidopsis thaliana. Int J Plant Sci 165: 231-242.

KINSMAN, E.A., and PYKE, K.A. (1998). Bundle sheath cells and cell-specific plastid development in Arabidopsis leaves. Development 125: 1815-1822.

KOIZUMI, K., SUGIYAMA, M. and FUKUDA, H. (2000). A series of novel mutants of Arabidopsis thalianathat are defective in the formation of continuous vascular network: calling the auxin signal flow canalization hypothesis into question. Development 127: 3197-3204

KONISHI, M. and YANAGISAWA, S. (2007). Sequential activation of two Dof transcription factor gene promoters during vascular development in Arabidopsis thaliana. Plant Physiol Biochem 45: 623-629.

LEE, J.Y., COLINAS, J., WANG, J.Y., MACE, D., OHLER, U. and BENFEY, P.N. (2006). Transcriptional and posttranscriptional regulation of transcription factor expression in Arabidopsis roots. Proc Natl Acad Sci USA 103: 6055-6060.

LIJAVETZKY, D., CARBONERO, P. and VICENTE-CARBAJOSA, J. (2003). Genome-wide comparative phylogenetic analysis of the rice and Arabidopsis Dof gene families. BMC Evol Bio/3: 17

MATTSSON, J., SUNG, Z.R. and BERLETH, T. (1999). Responses of plant vascular systems to auxin transport inhibition. Development 126: 2979-2991.

PETRICKA, J.J. and NELSON, T.M. (2007). Arabidopsis nucleolin affects plan development and patterning. Plant Physio/ 144: 173-186.

PINEAU, C., FREYDIER, A., RANOCHA, P., JAUNEAU, A., TURNER, S., LEMONNIER, G., RENOU, J.P., TARKOWSKI, P., SANDBERG, G., JOUANIN, L. et al. (2005). hca: an Arabidopsis mutant exhibiting unusual cambial activity and altered vascular patterning. Plant J44: 271-289.

SACHS, T. (1981). The control of the patterned differentiation of vascular tissues. Adv Bot Res 9: 151-262.

SAWA, S., KOIZUMI, K., NARAMOTO, S., DEMURA, T., UEDA, T., NAKANO, A and FUKUDA, H. (2005). DRP1A is responsible for vascular continuity synergistically working with VAN3 in Arabidopsis. Plant Physio/138: 819-826.

SAWCHUK, M.G., DONNER, T.J., HEAD, P. and SCARPELLA, E. (2008). Unique and overlapping expression patterns among members of photosynthesisassociated nuclear gene families in Arabidopsis. Plant Physio/148: 1908-1924.

SAWCHUK, M.G., HEAD, P., DONNER, T.J. and SCARPELLA, E. (2007). Timelapse imaging of Arabidopsis leaf development shows dynamic patterns of procambium formation. New Phyto/176: 560-571.

SCARPELLA, E., FRANCIS, P. and BERLETH, T. (2004). Stage-specific markers define early steps of procambium development in Arabidopsis leaves and 
correlate termination of vein formation with mesophyll differentiation. Development 131: 3445-3455.

SCARPELLA, E., MARCOS, D., FRIML, J. and BERLETH, T. (2006). Control of leaf vascular patterning by polar auxin transport. Genes Dev20: 1015-1027.

SCHMID, M., DAVISON, T.S., HENZ, S.R., PAPE, U.J., DEMAR, M., VINGRON, M., SCHOLKOPF, B., WEIGEL, D. and LOHMANN, J.U. (2005). A gene expression map of Arabidopsis thaliana development. Nat Genet 37: 501-6.

SIEBURTH, L.E. (1999). Auxin is required for leaf vein pattern in Arabidopsis. Plant Physiol 121: 1179-1190.

SHIGYO, M., TABEI, N., YONEYAMA, T. and YANAGISAWA, S. (2007). Evolutionary processes during the formation of the plant-specific Dof transcription factor family. Plant Cell Physio/48: 179-185.

SKIRYCZ, A., JOZEFCZUK, S., STOBIECKI, M., MUTH, D., ZANOR, M.I., WITT, I. and MUELLER-ROEBER, B. (2007). Transcription factor AtDOF4;2 affects phenylpropanoid metabolism in Arabidopsis thaliana. New Phytol 175: 425438.

SKIRYCZ, A., RADZIEJWOSKI, A., BUSCH, W., HANNAH, M.A., CZESZEJKO, J., KWASNIEWSKI, M., ZANOR, M.I., LOHMANN, J.U., DE VEYLDER, L., WITT, I. et al. (2008). The DOF transcription factor OBP1 is involved in cell cycle regulation in Arabidopsis thaliana. Plant J56: 779-792.

SKIRYCZ, A., REICHELT, M., BUROW, M., BIRKEMEYER, C., ROLCIK, J., KOPKA, J., ZANOR, M.I., GERSHENZON, J., STRNAD, M., SZOPA, J. et al. (2006). DOF transcription factor AtDof1.1 (OBP2) is part of a regulatory network controlling glucosinolate biosynthesis in Arabidopsis. Plant J47: 10-24.

SMITH, G.H. (1934). Anatomy of the embryonic leaf. Am J Bot21: 194-209.

STEINMANN, T., GELDNER, N., GREBE, M., MANGOLD, S., JACKSON, C.L.,
PARIS, S., GALWEILER, L., PALME, K. and JURGENS, G. (1999). Coordinated polar localization of auxin efflux carrier PIN1 by GNOM ARF GEF. Science 286: 316-318.

STEYNEN, Q.J., and SCHULTZ, E.A. (2003). The FORKED genes are essential for distal vein meeting in Arabidopsis. Development 130: 4695-4678.

TELFER, A. and POETHIG, R.S. (1994). Leaf development in Arabidopsis. In Arabidopsis. (eds. E.M. Meyerowitz and C.R. Somerville), pp. 379-401. Cold Spring Harbor: Cold Spring Harbor Press.

WARD, J.M., CUFR, C.A., DENZEL, M.A. and NEFF, M.M. (2005). The Dof transcription factor OBP3 modulates phytochrome and cryptochrome signaling in Arabidopsis. Plant Cel/17: 475-485.

WENZEL, C.L., SCHUETZ, M., YU, Q. and MATTSSON, J. (2007). Dynamics of MONOPTEROS and PIN-FORMED1 expression during leaf vein pattern formation in Arabidopsis thaliana. Plant J49: 387-398.

WINTER, D., VINEGAR, B., NAHAL, H., AMMAR, R., WILSON, G.V. and PROVART, N.J. (2007). An «electronic fluorescent pictograph» browser for exploring and analyzing large-scale biological data sets. PLOS ONE2: e718.

YANAGISAWA, S. (2002). The Dof family of plant transcription factors. Trends Plant Sci7: 555-560.

ZHANG, C., GONG, F.C., LAMBERT, G.M. and GALBRAITH, D.W. (2005). Cell type-specific characterization of nuclear DNA contents within complex tissues and organs. Plant Methods 1: 7

ZHAO, C., CRAIG, J.C., PETZOLD, H.E., DICKERMAN, A.W. and BEERS, E.P. (2005). The xylem and phloem transcriptomes from secondary tissues of the Arabidopsis root-hypocotyl. Plant Physio/138: 803-818. 


\section{Further Related Reading, published previously in the Int. J. Dev. Biol.}

See Special Issue Plant Development, edited by José L. Micol and Miguel A. Blázquez at:

http://www.ijdb.ehu.es/web/contents.php?vol=49\&issue=5-6

Lessons from a search for leaf mutants in Arabidopsis thaliana

José Manuel Pérez-Pérez, Héctor Candela, Pedro Robles, Víctor Quesada, María Rosa Ponce and José Luis Micol

Int. J. Dev. Biol. (2009) 53: 1623-1634

Alteration of the shoot radial pattern in Arabidopsis thaliana by a gain-of-function allele of the class III HD-Zip gene INCURVATA4 Isabel Ochando, Santiago González-Reig, Juan-José Ripoll, Antonio Vera and Antonio Martínez-Laborda

Int. J. Dev. Biol. (2008) 52: 953-961

Leaf shape: genetic controls and environmental factors

Hirokazu Tsukaya

Int. J. Dev. Biol. (2005) 49: 547-555

Genetic architecture of leaf morphogenesis in Arabidopsis thaliana

P Robles, JM Perez-Perez, H Candela, V Quesada, JM Barrero, S Jover-Gil, MR Ponce, JL Micol

Int. J. Dev. Biol. (2001) 45: S61-S62

Isolation and characterization of fast-neutron induced mutants with abnormal leaf morphology in Arabidopsis thaliana P Robles, JL Micol

Int. J. Dev. Biol. (2001) 45: S59-S60

Genetic and molecular analysis of INCURVATA2, a negative regulator of floral homeotic genes in the leaves of Arabidopsis thaliana MR Ponce, JM Barrero, H Candela, P Robles, JM Perez-Perez, P Piqueras, A Martinez-Laborda, JL Micol

Int. J. Dev. Biol. (2001) 45: S53-S54

ULTRACURVATA1, a SHAGGY-like Arabidopsis gene required for cell elongation

JM Perez-Perez, MR Ponce, JL Micol

Int. J. Dev. Biol. (2001) 45: S51-S52

Mutations in the ULTRACURVATA2 gene of Arabidopsis thaliana, which encodes a FKBP-like protein, cause dwarfism, leaf epinasty and helical rotation of several organs

JM Perez-PerezM, R Ponce, JL Micol

Int. J. Dev. Biol. (2001) 45: S49-S50

Interactions between venation pattern formation genes in Arabidopsis thaliana

H Candela, A Martinez-Laborda, JL Micol

Int. J. Dev. Biol. (2001) 45: S35-S36
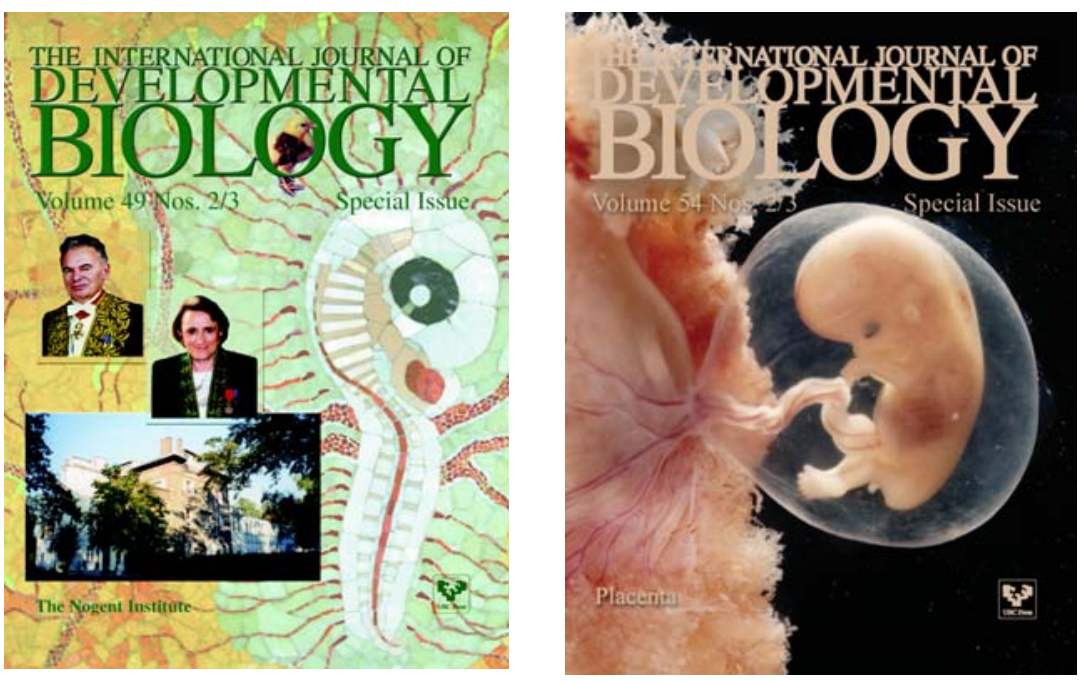

5 yr ISI Impact Factor $(2009)=3.253$
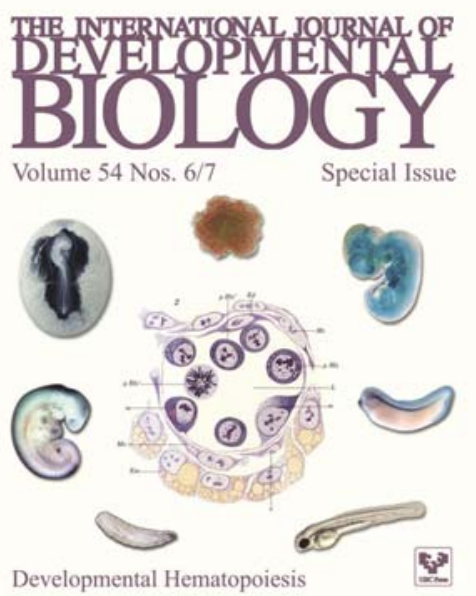